\title{
A Constant Grid Interface Current Controller for DC Microgrid
}

\author{
Muhannad Alshareef, and Zhengyu Lin \\ Power Electronics ,Machine and Power System Group \\ Aston University \\ Birmingham , UK \\ alsharem@aston.ac.uk
}

\begin{abstract}
With the increased percentage of distributed renewable energy sources (RES) connected to the power network, it is challenging to maintain the balance between the power generation and consumptions against the unpredictable renewable energy generation and load variations. Considering this, this study proposed a new DC microgrid control strategy to reduce the disturbance to the main power grid from the distributed generation and load variations within the DC microgrid. The DC microgrid model used in this study includes an energy storage unit (battery), a distributed generation unit (PV) and loads. A fuzzy logic controller (FLC) is used to actively regulate the battery charging/discharging current to absorb the power variation caused by PV generation and load changes. The proposed control strategy is validated by simulation in MATLAB/Simulink.
\end{abstract}

Keywords_DC microgrid ; Fuzzy logic control ; Energy Stoarge.

\section{INTRODUCTION}

Microgrids, which consist of distributed power generation, energy storages and loads, are power network sub-systems that can be independently controlled [1], and can be operated in both grid-connected or island mode. Grid-connected microgrid is one of the key technologies to realize the potential benefits of distributed renewable generation. Lately, increasing attention has been paid to the research on DC microgrids. Compared to AC microgrids, DC microgrids are less complex, better integration with DC distributed RES and energy storage, and require fewer stages for power conversion. Due to these properties, DC microgrids are more efficient, secure and flexible [2-3].

Microgrids have the advantages to better integrate renewable energy to the main grid [4]. With the increased percentage of distributed renewable generations connected to the power network, the grid operation faces new challenges. For example, it has been reported that PV generation injecting an exceedingly distorted current into the grid [5]. The impacts of the increasing PV generation on the grid has been investigated, and based on the findings of various studies, several control techniques have been developed to reduce the disturbance to the grid, which include sliding mode control [6], Droop control [7], and feedback linearizing control [8]. In each case, these control techniques are integrated with the battery charging/discharging

This work has received funding from the European Union's Horizon 2020 research and innovation programme under grant agreement No 734796. controllers to absorb the PV fluctuation. Furthermore, a power management scheme (PMS) is proposed in [9] for two different hybrid ac/dc microgrids, and proposed a multi-time scale adaptive droop control strategy. It plays a key role in power regulation under different loads and PV fluctuations scenarios. In [10], a droop control is developed by means of advanced model predictive control (AMPC) for smart DC microgrid to enable a fast control due to the nature of this controller. In [11], a conventional PI controller was proposed for both battery and supercapacitor controllers to absorb the fluctuating during PV power variation.

The above mentioned previous studies are mainly the implementation of various control strategies to regulate DC bus voltage in DC microgrids against load or PV fluctuations. These methods must has a full acknowledge of system parameters, but due to the system's non-linearity and variation, the relevant calculations are often complex. Compared to those techniques, the utilization of fuzzy logic controllers (FLCs) has been proposed as a way to deal with the non-linearity of the system, and at the same time, to absorb the fluctuations within the microgrid [12-18]. FLCs can efficiently handle non-linear systems, without the knowledge of the system parameters. Additionally, when fine-tuned, FLCs tend to outperform conventional controllers [19-20].

A typical DC microgrid block diagram is shown in figure 1, and all components are connected to a common DC bus via DC/DC converters, which will bring the benefit of higher efficiency and lower cost. The DC microgrid connect to a main DC grid directly through an inductor filter. This study will focus on the control strategy for the interface current between the DC microgrid and the main DC grid. A novel control strategy will then be proposed to minimise the disturbance to the main DC grid from the PV and loads variations inside the DC microgrid. A simple DC microgrid system, which consists of a battery energy storage, a PV power generation, and local loads, will be modelled and investigated in Matlab/Simulink to validate the proposed control algorithm.

\section{DC MICROGRIDS STRUCTURE}

Fig. 1 shows the block diagram of the DC microgrid considered in this study in grid-connected mode. The microgrid comprises a PV panel, as a renewable energy source, and battery bank as an energy storage unit. In this configuration, the PV panel is 
connected to the common DC bus via a Boost converter, and the battery bank connected to the DC bus via a Buck-Boost converter.

\section{A- PV panal analysis}

A PV panel is comprising a series of solar cells, and PV generation has many advantages over traditional power generation methods, including their quiet operation, the lack of pollution, free natural availability and not requiring fuel. Papers [21-22] describe the non-linear current-voltage relationship of PV arrays.

The output voltage of the PV panel, $\mathrm{V}_{\mathrm{PV}}$ is given by:

$V_{P V}=n_{S}\left(\frac{N k T}{q}\right) \ln \left\{\frac{\left(n_{P} I_{L}\right)-I_{P V}+\left(n_{P} I_{S}\right)}{n_{P} I S}\right\}-\frac{n_{S}}{n_{P}} I_{P V} R_{S}$

where $V_{P V}$ and $I_{P V}$ are the output voltage and current of the PV array, $I_{S}$ is the saturation current, $n_{S}$ and $n_{P}$ are the numbers of series and shunt linked modules per string, $k$ is the junction factor of the solar cells, $Q$ is the electron charge, $I_{L}$ is the current produced by light in the PV cells and $R_{S}$ is the series resistance, and $T$ is the temperature in kelvin.

The power produced by the $\mathrm{PV}$ system, $P_{P V}$, is given by Equation (2):

$$
P_{P V}=V_{P V} \times I_{P V}
$$

Equations (1) and (2) together describe the non-linear powervoltage behavior of PV systems. The relationships between each of these factors are plotted in Fig. 2; the maximum power point (MPP) is determined by the characteristic curves for a range of different weather conditions.

\section{B. Lead acid Battery}

Lead acid batteries are used as the energy storage, and they are connected to the common DC bus via a bidirectional DC/DC converter. A novel battery charging/discharging control strategy is integrated to the battery controller to absorb the fluctuations caused by the intermittent and uncertain nature of PV output power and as well as variable load demands. The battery model is taken from Matlab/Simulink library.

\section{THE PROPOSED CONTROL ALGORITHMS}

In the proposed control strategy, the battery charging/ discharging current will be actively regulated in order to comply with the load and PV generation fluctuations, thereby maintaining the stability of the interface current between the DC microgrid and the main DC grid.

As shown in fig. 1, the interface current between the DC microgrid and the main DC grid is denoted as $I_{P L}$. The interface current can be affected by the load or PV generation variations. This study aims to prevent the transfer of this PV and load disturbances to the main DC grid by maintain the interface current $I_{P L}$ as a constant. Therefore, the DC/DC converter for the battery requires an appropriate control algorithm.

In this study, a FLC is applied in order to control the battery charging/discharging current, thus achieving a constant interface current from the DC microgrid to the main DC grid.
Fig. 3 shows the block diagram of the FLC in this study. The reference interface current $\left(I_{P L}\right.$ ref $)$ is compared with the actual interface current $\left(I_{P L}\right)$ to produce the error signal $e(t)$, where $\Delta e$ denotes the change of the error signals. Two FLCs were used in the control system, one for battery charging mode (FLC\#1) and another for battery discharging mode (FLC\#2). The inputs for the first $F L C \# 1$ are $e_{1}(t)$ and $\Delta e_{1}(t)$, while the inputs for the second FLC\#2 are $e_{2}(t)$ and $\Delta e_{2}(t)$. The outputs of the FLC $\left(\Delta d(t)_{\text {Boost }}\right.$ and $\left.\Delta d(t)_{\text {Buck }}\right)$ are used to update the duty cycle $d(t)_{\text {Boost }}$ and $d(t)_{\text {Buck }}$ correspondingly, which will be compared with triangular carrier waveform to produce PWM for the DC/DC converter.

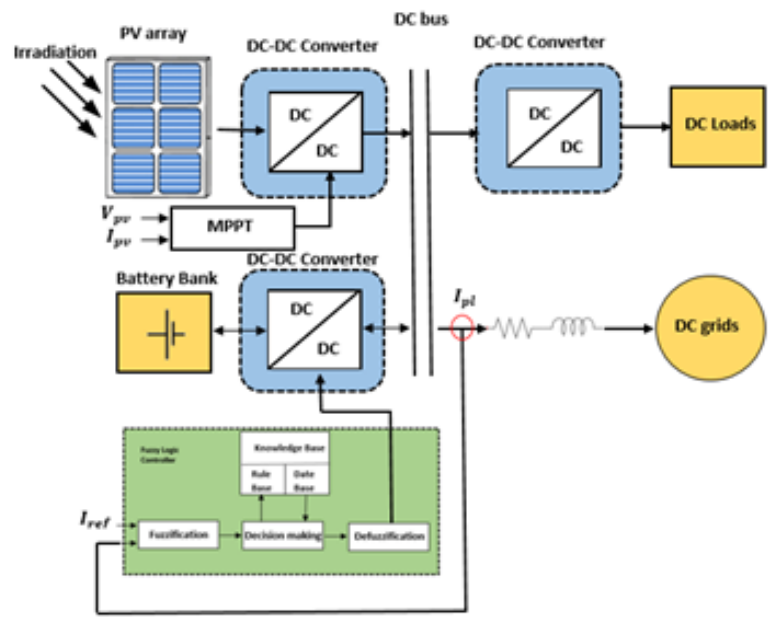

Fig 1. A typical DC microgrid



Fig. 2: P-V characteristic curves of PV array.

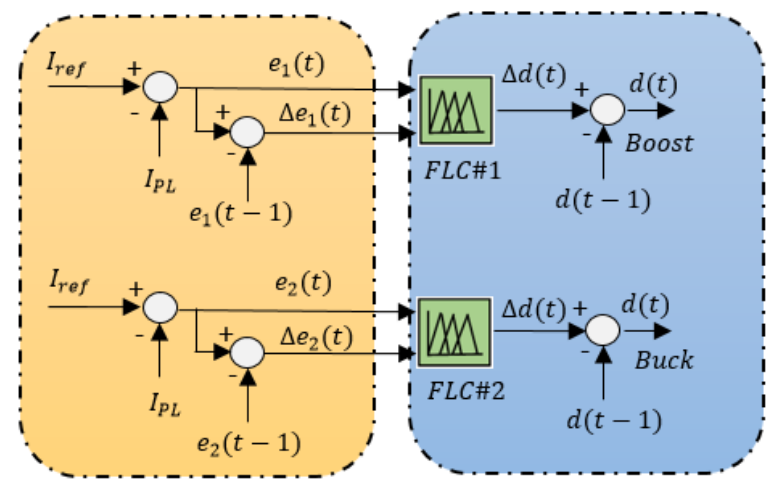

Fig. 3: Block diagram of proposed FLC controller.

Seven fuzzy subsets are obtained from the categorisation of the variable inputs and output, namely, negative big (NBIG), 
negative medium (NM), negative small (NS), zero (ZE), positive small (PS), positive medium (PM), and positive big (PBIG). The fuzzy rules involves 49 fuzzy control rules, based on the IF-THEN rules and defined in table (1).

The proposed FLC exploits the link between error $(e)$ and change of error $(\Delta e)$ to achieve tuning of the DC/DC converter duty cycle, and the FLC parameters will be adapted online by the interface current and control. In the defuzzification stage, the output of FLC is changed from linguistic variables to numerical variables. In this study, Mamdani's method is used for fuzzification, and centre of gravity method is used for defuzzification to get the duty cycle (d). Furthermore, the representation of the membership functions of both input and output variables is based on symmetric trapezoidal functions and can be seen in fig. 4 .

The rule surface of the Fuzzy logic controller can be seen in fig. 5 , after all of the membership functions and rules have been defined.

$$
\begin{gathered}
e=I_{\text {ref }}(k)-I_{P L}(k) \\
\Delta e=e(k)-e(k-1) \\
d(k)=d(k-1)+(n \Delta d(k))
\end{gathered}
$$

where $\Delta d(t)$ is the variation of duty cycle, $\mathrm{K}$ is the sampling time, and $\mathrm{n}$ is the gain factor of FLC controller.

The structure of the FLC rules is experiential in nature and based on the following conditions:

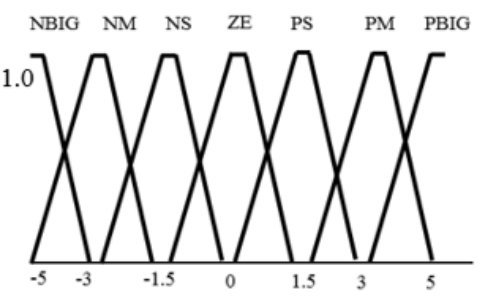

(a)

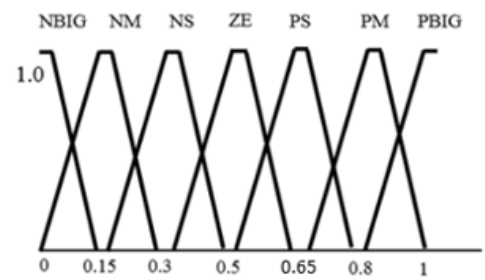

(b)

Fig. 4: membership functions of the FLC (a) input variables (a) output variable.

TABLEI. THE LIST OF FUZZY RULES

\begin{tabular}{|c|c|c|c|c|c|c|c|}
\hline N & NBIG & NM & NS & ZE & PS & PM & PB \\
\hline NBIG & NBIG & NBIG & NBIG & NBIG & NM & NS & ZE \\
\hline NM & NBIG & NBIG & NBIG & NM & NS & ZE & PS \\
\hline NS & NBIG & NBIG & NM & NS & ZE & PS & PM \\
\hline ZE & NBIG & NM & NS & ZE & PS & PM & PBIG \\
\hline PS & NM & NS & ZE & PS & PM & PBIG & PBIG \\
\hline PM & NS & ZE & PS & PM & PBIG & PBIG & PBIG \\
\hline PBIG & ZE & PS & PM & PBIG & PBIG & PBIG & PBIG \\
\hline
\end{tabular}

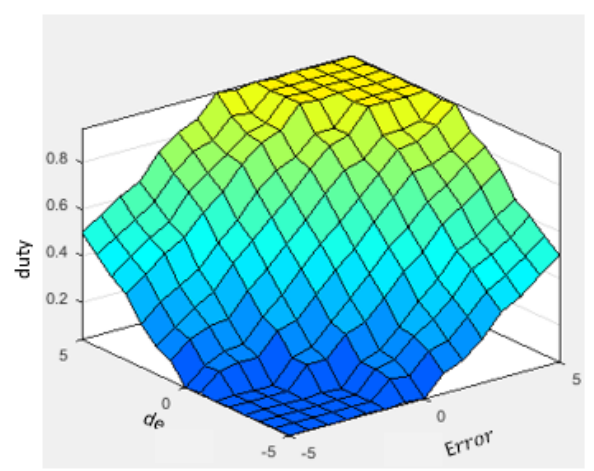

Fig. 5: shows the 3D rule surface of FLC system

- A large changed of the duty cycle is required to bring the output of the buck-boost converter to the set point rapidly, when the measured grid interface current is far from the reference current.

- A small variation of the duty cycle is needed, when the measured grid current is approaching the reference current.

- The duty cycle must be unchanged to avoid the overshoot when the measured grid current is near the reference grid current and is approaching it quickly.

- The duty cycle must be constant, when the FLC controller succeeded for absorbing the PV generation and load fluctuations and the measured grid current is being stable.

- When the measured grid current is above the reference current due to change in the PV output power, the duty cycle must be changed with negative sign and vice versa.

\section{Simulation AND RESUlts}

A simple DC microgrid and the proposed FLC based battery current controller were modelled in Matlab/Simulink, with the simulation system parameters being indicated in Table 2. The simulation included two scenarios, and a performance comparison was undertaken between the proposed FLC and a well-designed PID controller. Furthermore, the open and closed-loop bode plot for the bi-directional converter can be seen in fig. 6(a), where the controller has high gain margin and phase margin with 38.7 deg.

\section{Scenario one}

To examine how the interface current between DC microgrid and the main DC grid is affected by PV generation, the PV output with variable irradiance profile has been tested. The interface current controller is under conventional PID control. Variation in the irradiation occurs at $t=0.2 \mathrm{~s}$. The simulation results when the irradiation declines is presented in Figure 7(a), which shows that a step decrease in PV current from $7.5 \mathrm{~A}$ to 3.9 A with constant grid interface current and battery is in discharging mode. Meanwhile, the simulation results when the irradiation increases is presented in Figure 7(b), which shows that the PV current undergoes a step increase from 3.9 A to 8 
A, with fixed grid interface current and battery is in charging mode. The simulation results show the conventional PID based battery charging/discharging current controller can regulate the interface current to absorb PV generation fluctuations, but with a relative large transient disturbance.

The interface current control results under the proposed PLC controller is shown in fig. 8. Compared to the conventional PID controller, the proposed FLC not only demonstrates a higher performance and remains constant when irradiation fluctuates (as shown in fig. 8), but also overcomes the limitations of the PID controller such as: overshoot and steady state error. Furthermore, under conditions of PV fluctuations, the interface current is well regulated by the FLC.

TABLE II.THE PARAMETERS OF THE DC MICROGRID SUBJECTED TO SIMULATION

\begin{tabular}{|c|c|}
\hline \multicolumn{2}{|c|}{ System specifications } \\
\hline DC bus & Rated voltage: $48 \mathrm{v}$ \\
\hline PV array & $\begin{array}{c}\text { Module type: BP solar SX 3190 } \\
\text { with Vmpp= } 24.3 \mathrm{v} \text { Impp= } 7.82 \mathrm{~A} .\end{array}$ \\
\hline Energy Storage & Battery: lead acid with $24 \mathrm{v} / 10 \mathrm{~A} / \mathrm{h}$ \\
\hline DC Loads & 50 Watts \\
\hline
\end{tabular}

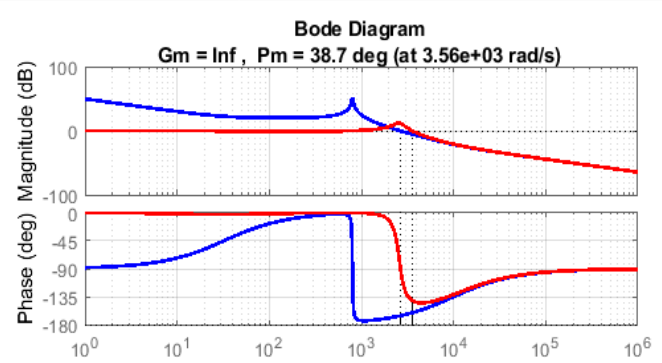

(a)

\begin{tabular}{|c|ccc|}
\hline Controller & \multicolumn{3}{|c|}{ Parameters } \\
\hline \multirow{2}{*}{ PID } & $\boldsymbol{K}_{p}$ & $\boldsymbol{K}_{\boldsymbol{i}}$ & $\boldsymbol{K}_{\boldsymbol{d}}$ \\
\cline { 2 - 4 } & 100 & 0.01 & 0.02 \\
\hline
\end{tabular}

(b)

Fig. 6: (a) open-loop and-closed loop bode diagram for the battery converter. (b) PID controller parameters.
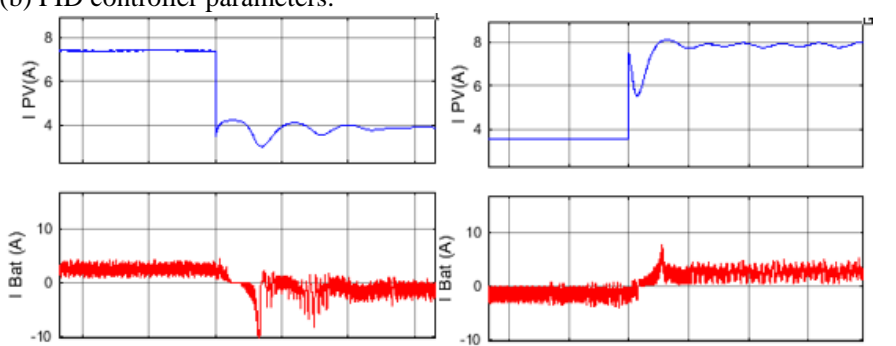

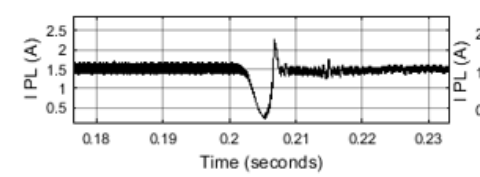

(a)

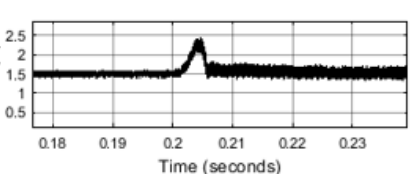

(b)
Fig. 7: PV current, battery current and interface current with the conventional controller under conditions of reduced PV generation (a) and increased PV generation (b).

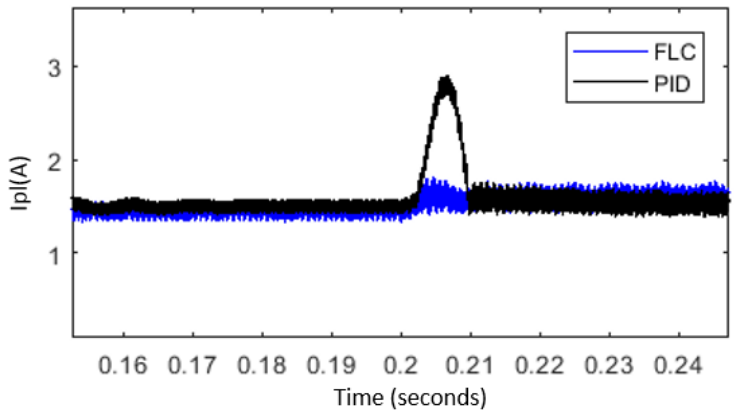

(a)

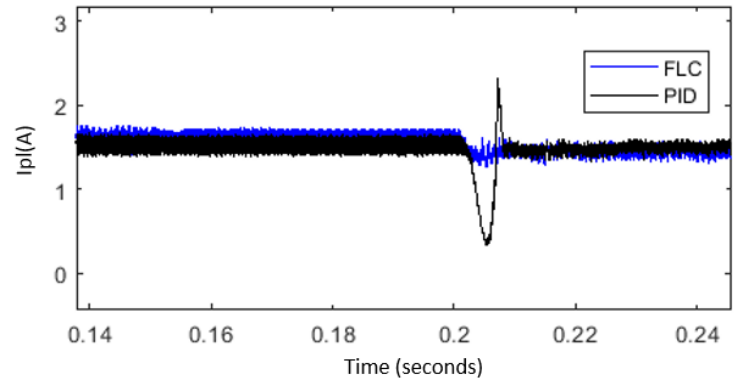

(b)

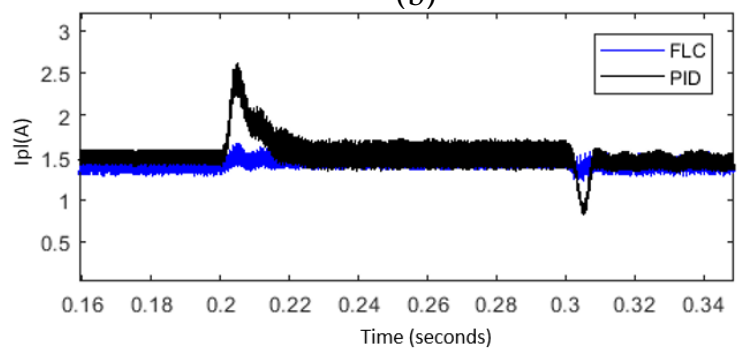

(c)

Fig. 8: PID controller and FL controller compared in terms of grid interface current: (a) with raised PV generation, (b) reduced PV generation, and (c) raised PV from $500 \mathrm{w} / \mathrm{m}^{2}$ to $1000 \mathrm{w} / \mathrm{m}^{2}$ before decreasing it to $700 \mathrm{w} / \mathrm{m}^{2}$.

\section{Scenario two}

For scenario two, the conditions is that the DC load current varies, while the PV output current maintain constant. In the simulation study, the load change occurs at $t=0.2 \mathrm{~s}$, the load resistance fell from $50 \Omega$ to $16.7 \Omega$, or changed from $25 \Omega$ to $50 \Omega$.

Figure 9 shows the simulation results of the interface current under the control of the proposed FLC controller, for both above two test conditions. It is observed that under the load current changing conditions, the proposed PLC controller can be activated in response to these variations by actively charging or discharging the battery. The interface current can be regulated by the FLC within a couple of milliseconds with a low overshoot following the occurrence of the disturbance. Thus, the proposed FLC is capable of maintaining the DC microgrid interface current constant regardless of the PV and loads fluctuations.

Figure 10 shows the comparison of the control performance between the conventional PID controller and the proposed FLC. It shows the proposed FLC has a better and more robust performance. 




(a)

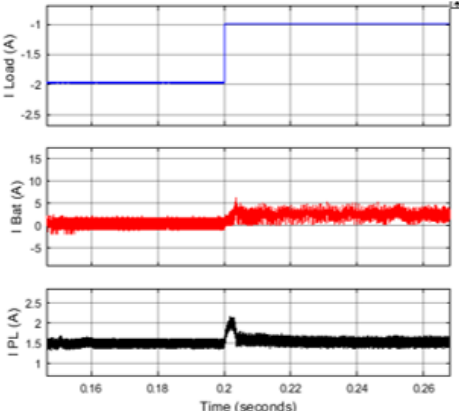

(b)
Fig. 9: Load current, battery current and interface current with the conventional controller under conditions of reduced load demand (a) and increased load demand (b)

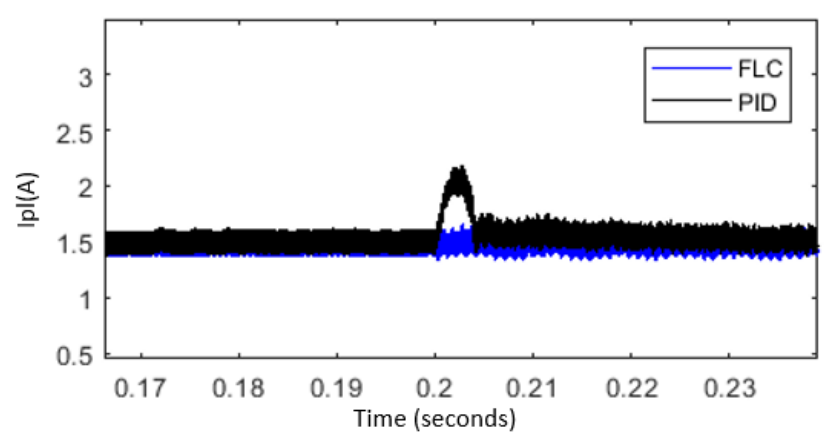

Fig. 10: PID controller and FL controller compared in terms of grid interface current with changed load demand.

\section{CONCLUSIONS}

A novel DC microgrid control strategy is propose in this study to prevent the PV and load fluctuations from transferring to the main DC grids. To facilitate the absorption of PV and load disturbances, a fuzzy logic controller is proposed for the battery bidirectional power converter control. Furthermore, Matlab/ Simulink is used to simulate the proposed controller to evaluate the feasibility and effectiveness. According to the findings obtained with the proposed current controller, the batteries controller can absorb the disturbances caused by PV and loads variations and prevent them to be transferred to the main grid.

In the simulation studies, the performance of the two controllers was tested compared. It shows that the proposed Fuzzy logic controller is capable for keep the interface current stable under PV and loads variations. Furthermore, it has better performance and more robust than the PID controller. The FLC can effectively control the interface current within a few milliseconds after the variations happening. From the dynamic response perspective, the response of the DC microgrids system with FLC controller has excellent transient performance with lower overshoot, rise and settling time.

\section{REFERENCES}

[1] R.H. Lasseter, "Microgrids", in IEEE Power Engineering Society Winter Meeting, vol. 1, pp. 146-9, 2001

[2] D. Salomonsson, L. Soder and A. Sannino, "Protection of Low-Voltage DC Microgrids," in IEEE Transactions on Power Delivery, vol. 24, no. 3, pp. 1045-1053, July 2009.
[3] R. M. Cuzner and G. Venkataramanan, "The Status of DC Micro-Grid Protection," 2008 IEEE Industry Applications Society Annual Meeting, Edmonton, Alta., 2008, pp. 1-8.

[4] J. R. Agüero and S. J. Steffel, "Integration challenges of photovoltaic distributed generation on power distribution systems," 2011 IEEE Power and Energy Society General Meeting, San Diego, CA, 2011, pp. 1-6

[5] J. Desmet, C. Debruyne, J. Vanalme, and L. Vandevelde, "Power injection by distributed generation and the influence of harmonic load conditions," in Power and Energy Society General Meeting, 2010 IEEE, 2010, pp. 1-6, Minneapolis, MN.

[6] U. K. Kalla, B. Singh and S. S. Murthy, "Slide mode control of microgrid using small hydro driven single-phase SEIG integrated with PV array," in IET Renewable Power Generation, vol. 11, no. 11, pp. 1464-1472, 2017.

[7] R. K. Sharma, S. Mudaliyar and S. Mishra, "Power management and economic load dispatch based control of hybrid PV-battery-diesel standalone AC system," 2018 IEEMA Engineer Infinite Conference (eTechNxT), New Delhi, India, 2018, pp. 1-6.

[8] Mahmud, M., Roy, T., Islam, S., Saha, S. and Haque, M. " Nonlinear Decentralized Feedback Linearizing Controller Design for Islanded DC Microgrids, " 2017 Electric Power Components and Systems, 45(16), pp.1747-176.

[9] R. K. Sharma and S. Mishra, "Dynamic Power Management and Control of a PV PEM Fuel-Cell-Based Standalone ac/dc Microgrid Using Hybrid Energy Storage," in IEEE Transactions on Industry Applications, vol. 54, no. 1, pp. 526-538, Jan.-Feb. 2018.

[10] M. B. Shadmand, R. S. Balog and H. Abu-Rub, "Model Predictive Control of PV Sources in a Smart DC Distribution System: Maximum Power Point Tracking and Droop Control," in IEEE Transactions on Energy Conversion, vol. 29, no. 4, pp. 913-921, Dec. 2014.

[11] Jayalakshmi N. S., D. N. Gaonkar, Vikash Kumar J. and Karthik R. P., "Battery-ultracapacitor storage devices to mitigate power fluctuations for grid connected PV system," 2015 Annual IEEE India Conference (INDICON), New Delhi, 2015, pp. 1-6.

[12] A. Benyamina, S. Moulahoum, I. Colak and R. Bayindir, "Hybrid fuzzy logic-artificial neural network controller for shunt active power filter," ICRERA 2016, Birmingham, pp. 837-844.

[13] K. Basaran and N. S. Cetin, "Designing of a fuzzy controller for grid connected photovoltaic system's converter and comparing with PI controller," 2016 IEEE International Conference on Renewable Energy Research and Applications (ICRERA), Birmingham, 2016, pp. 102-106.

[14] A. Benyamina, S. Moulahoum, I. Colak, N. Kabache and H. Houassine, "Design and experimental implementation of single phase power factor correction converter based on fuzzy logic controls techniques," 2015 International Conference on Renewable Energy Research and Applications (ICRERA), Palermo, 2015, pp. 838-844.

[15] S. Sahoo, B. Subudhi and G. Panda, "Comparison of Output Power Control Performance of Wind Turbine using PI, Fuzzy Logic and Model Predictive Controllers", International Journal of Renewable Energy Research, vol. 8, no. 2, 2018.

[16] B. Naick, T. Chatterjee and K. Chatterjee, "Fuzzy Logic Controller based PV System Connected in Standalone and Grid Connected Mode of Operation with Variation of Load", International Journal of Renewable Energy Research, vol. 7, no. 1, 2017.

[17] Y. Allahvirdizadeh, et. al., "Study of Energy Control Strategies for a Standalone PV/FC/UC Microgrid in a Remote Area", International Journal of Renewable Energy Research, vol. 7, no. 3, 2017.

[18] C. ed-dahmani and H. Mahmoudi, "A Comparative Study of Fuzzy Logic Controllers for Wind Turbine Based on PMSG", International Journal of Renewable Energy Research, vol. 8, no. 3, 2018.

[19] M. Jama, A. Assi, A. Wahyudie and H. Noura, "Self-tunable fuzzy logic controller for the optimization of heaving wave energy converters," 2012 ICRERA 2012, Nagasaki, pp. 1-6.

[20] Y. Soufi, M. Bechouat, S. Kahla and K. Bouallegue, "Maximum power point tracking using fuzzy logic control for photovoltaic system," ICRERA 2014, Milwaukee, pp. 902-906.

[21] Kamal, T. and Hassan, S. (2016). Energy Management and Simulation of Photovoltaic/Hydrogen/Battery Hybrid Power System. Advances in Science, Technology and Engineering Systems Journal, 1(2), pp.11-18.

[22] Hassan, S. (2016). CONTROL AND ENERGY MANAGEMENT SCHEME FOR A PV/SC/BATTERY HYBRID RENEWABLE POWER SYSTEM. Science International. 28. 955-964. 